\title{
Forms of Demographic Cooperation in Scandinavia
}

\author{
By GUNNAR FOUGSTEDT
}

Swedish School of Economics, Helsinki, Finland

Demography is a science with rather few practicians in the Scandinavian countries. In our countries, no foundation has been found for demographic associations or demographic journals. For example, we have not a single professorial chair of demography in the whole of Scandinavia. For the small number of Scandinavian demographers, accordingly, the exercise of scientific contact beyond the confines of their own borders is of even more importance than for the representatives of sciences with a broader anchorage.

To a major extent, demographers are concerned with a material which relates to the country itself, and the results thereby arrived at, in many cases, do not possess the same general validity as the research findings of natural scientists and technologists. Nevertheless, it can also be stated that a demographic investigation gains a great deal in interest if the results can be compared with corresponding results from other countries with similar conditions.

I can mention the following conceivable forms of cooperation in demography between the Scandinavian countries:

1) teaching which is to a certain extent coordinated

2) joint research projects

3) unified concepts and classifications

4) exchange of information

5) joint Scandinavian publications

6) conferences and symposia

7) a common organisation

8) a common representation to other countries

These forms of cooperation are treated below in order.

1. Teaching in demography is on many different planes. The need for Scandinavian cooperation appears to be greatest at the highest level: in the academic training of demographers, and of persons who wish to take demography as their most important subsidiary subject, say on a 2-certificate level. As was mentioned above, there is no professor in 
demography in the Scandinavian universities. Nevertheless, at the University of Gothenburg, demography has been accorded so independent a position that one can there sit for the licentiate degree with demography as the main subject. At a meeting held by the Scandinavian research council for the social sciences, at Holmenkollen in 1964, a resolution was adopted for recommendation of the establishment of a professor in demography at the University of Gothenburg. I believe that in the long run we cannot feel satisfied with this objective, but must endeavour to get a professor in each and every one of the Scandinavian countries - with Iceland perhaps excepted. However, this can demand a long time, and thus we can be glad of the opportunity afforded to study demography at the University of Gothenburg, which stands open to students from all the Scandinavian countries. The doctoral dissertations in demography which have been published in our countries have had to sail "under false colours", and have been referred to such subjects as statistics, sociology, geography and economics. At the Scandinavian institute for community planning, to begin operations in Stockholm in the autumn, it is clear that demography must assume a prominent place in the curriculum.

2. The possibility of carrying out joint demographic research projects has been considerably increased through the agency of the important research grants which can nowadays be obtained from the Nordic Cultural Fund. The initiative for such projects could very well originate in a small group of demographers from different Scandinavian countries, who know each other well, and who can agree on a joint programme. In some individual cases, one could think, perhaps, of more comprehensive projects, formulated by a larger - temporary or permanent - organisation.

3. The unification of demographic concepts has profited from the demographic dictionary, published by UN in French, English and Spanish, and which has, on the intiative of Scandinavian demographers, also been published in Swedish and Finnish versions. The unification of classifications has taken place partly under the direction of UN, and partly in the form of Scandinavian cooperation in the Scandinavian committee for population statistics.

4. The exchange of information could proceed, among other ways, in the form of demographic bibliographies, which could be formulated in the different Scandinavian countries. It may be mentioned that the Population Research Institute (Väestöpoliittinen tutkimuslaitos) in Helsinki has in its yearbook published a comprehensive bibliography of newly issued demographic literature in Finland. The latest bibliography, which relates to $1960-64$, includes 397 numbers. I am unaware whether similar bibliographies are formulated in other Scandinavian countries. In the yearbook mentioned, lists are also included of licentiate and graduate 
dissertations in demography, which have been prepared in Finland's institutes of advanced studies.

5. The question of a joint Nordic publication series (either a series of separate investigations, a yearbook, or an actual magazine) can be worth discussion, even if in the current situation we may not possess the intellectual and economic resources demanded by such an enterprise. Such a series of writings should be published in English, to ensure an international distribution. In Finland, plans are being nursed that the yearbook of Population Research in Finland, now published in Finnish with an English summary, should be published completely in English. It is by no means unthinkable that it would be able to publish the results of research in other Scandinavian countries.

6. If the symposium now in progress proves to fulfil the arrangers' expectations, it should not be an impossible task to continue this tradition with a joint Scandinavian symposium, say every third year. It is to be hoped that the Nordic Cultural Fund would in such a case show continued understanding of our need of financial support.

7. It might very well happen that such symposia could be arranged by ad hoc committees, even if a permanent organisation could introduce some advantages, including the planning and the applications for support. In the event that the wish existed for the achievement of more continuous demographic cooperation, it would appear necessary to have a permanent Scandinavian organisation of some kind. One possibility would be that those who are present here, along with the absent Scandinavian demographers who belong to the International Union for the Scientific Study of Population, could be offered the opportunity to become foundermembers of the "Scandinavian Demographic Society", so that this association could be started during the course of this symposium and acquire a board of management, consisting of one member from each Scandinavian country, plus a secretary from the chairman's country. It may be mentioned that the thought of a Scandinavian demographic society was discussed by the delegates to the World Population Conference in Belgrade in 1965. However, at that time the appeal did not get any response here at home. Perhaps it would go better now, when we see that a Scandinavian symposium can be arranged. A more cautious solution would be simply the appointment of a "contact man" in each country, and not the establishment of any association. But in such an event, how would a new contact man be appointed?

8. Among the functions which could most easily be attended to by a permanent organisation is that of common contact with the external world. By this means, for example, it would be possible to coordinate the visits of foreign demographers to the Scandinavian countries.

In conclusion, I should like to emphasise that intensified Scandinavian demographic cooperation should not be viewed as as an alternative to 
international and European cooperation. All of these forms of cooperation are required. But, in the same way as experience has shown that in some respects the European meetings have been more fruitful than international conferences, it is conceivable that that Scandinavian symposia, partly through their intimate nature, and partly by reason of the great similarities between our countries in a demorgraphic aspect as well, can be valuable and inspiring opportunities for contact.

NOTE. In July 1969 professor Hannes Hyrenius was appointed professor in demography at the University of Gothenburg and director of the Demographic Institute of the University. Thus, the first professorship in demography has been established in Scandinavia. 